\title{
Status and Perspectives of Commercial Aircraft Morphing
}

\author{
Michelangelo Giulianii $^{*}$, Ignazio Dimino ${ }^{2}$, Salvatore Ameduri ${ }^{2}$, Rosario Pecora ${ }^{3}$ and Antonio Concilio ${ }^{2}$ \\ 1 REDAM, Research and Development in Applied Mechanics, Avellino, Italy \\ Department of Adaptive Structures, The Italian Aerospace Research Centre (CIRA), Via Maiorise, 81043 \\ Capua, Italy; \\ 3 University of Naples "Federico II", Industrial Engineering Department, Via Claudio, 21 -80125- Napoli, \\ Italy* \\ Correspondence: info@redam.it;
}

\begin{abstract}
In a previous paper, the authors dealt with the current showstoppers for morphing systems and with the reasons that have inhibited their commercial applicability. In this work, the authors express a critical vision of the current status of the proposed architectures and the needs that should be accomplished to make them viable for installation onboard of commercial aircraft. The distinction is essential because military and civil issues and necessities are very different, and both the solutions and difficulties to be overcome are widely diverse. Yet, still remaining in the civil segment, there can be other differences, depending on the size of the aircraft, from large jets to commuters or general aviation, in turn classifiable in tourism, acrobatic, ultralight and so on, each with their own peculiarities. Therefore, the paper wants to try to trace a common technology denominator, if possible, and envisage a future perspective of actual applications.
\end{abstract}

Keywords: Morphing Wings, Adaptive Structures, Control Systems, Embedded Kinematics, Distributed Actuator and Sensor Networks

\section{Introduction}

Morphing wings are an excellent mean to increase aircraft performance, as demonstrated by many researches in the field. Indeed, the bibliography is rich in studies, attainments, and tests of devices implemented on significant mock-ups. Furthermore, the history of aviation itself counts many trials for installing variable-shape wings on the aircraft at different extents. However, as a critical classification of the accessible instruments and tools is tried, it is necessary to differentiate technology by size. In fact, one of the most relevant concepts in the field regards the proper scalability of the proposed architectures. Yet, this basic idea is not entirely assessed, in spite of some recent specialized publications on the matter. Because aerodynamics, mechanics, structural dynamics, aeroelasticity, and so on depend on different physical laws in turn involving a large number of diverse parameters, any result attained on a given configuration is not easily exportable to others. A direct consequence of this statement is that what is tested on models, or specific aircraft, is not generally transferrable to full-size systems, or different classes of planes. This fact implies huge complications of the design process. Therefore, as commercial aircraft is targeted, a filter shall be applied to cut or better evaluate many examples appearing in literature, even though relevant and fascinating. One of the most important factors that limits the actual development of the morphing technology is related to the necessity of performing a careful assessment of its impact on the aircraft in terms of benefits and drawbacks. This step is not trivial, and in turn, implies a precise definition of the vehicle mission or missions, where the targeted device is supposed to be employed, and a perspective of the consequence of the modified configuration on the whole operational envelop. Weight penalties, effects on safety inspections, and so on could determine the viability or not of a specific innovative system, and should always be evaluated versus the expected advantages. For instance, if an additional component could favor and simplify the take-off 
phase, it shall be demonstrated it does not negatively affect the other phases of the flight, neither the planned maintenance nor other aspects of the regulation requirements.

For instance, within the MAS project, funded by DARPA in the USA, NextGen Aeronautics developed an adaptive wing capable of largely modifying its aspect ratio [1]. The target was achieved by a truss system and a deformable skin that stretched and shrunk the wing to assume loitering or diving configurations, for instance. Another major example is given by the aircraft model recently developed and flown by NASA, where an adaptive winglet was used to change wingspan or assume positive or negative cant angles, depending on the flight necessities, [2]. Finally, NASA also exposed some years ago a futuristic architecture where elementary devices were combined together in order to provide almost continuous form variation to the hosting vehicle. Such a digital wing, as it was called, then evolved in a complete aircraft, all made of such simple subunits that were named voxel, perhaps recalling pixels in a usual digital image, [3]-[4]. A similar concept was also developed as a part of a multi-morph robotic system, [5].

There are many examples even concerning manned aircraft-size; indeed, such proposals run all over the flight history, starting from the 1910s and 1920s, [6]-[7]. In the first case ([6]), a patent was issued concerning kinematic systems made for modifying the external shape of the front and aft parts of the wing, while the second example ([7]) proposed a configuration able to self-adapt the profile of bi- and triplanes. A significant step was accomplished as the F111 was equipped with a wing capable of continuously varying its trailing and leading-edge cambers. The aircraft made a huge test campaign, which results are still a milestone in the sector of the adaptive aeronautic structures, [8]-[9]. The improved capability in loitering, diving, maneuvering was clearly assessed, finally demonstrating the potential of such an envisaged technology. It was only ten years later that a study was presented to illustrate the applicability of that concept to large-size commercial aircraft, along the wake of the development of the Airbus planes, [10]. Finally, large-size prototypes were assessed between 2015 and 2017, with two large projects in Europe and the USA. The EU SARISTU project designed, manufactured, and tested a full-size wing section in wind tunnel, demonstrating the feasibility of realizing an adaptive wing for commercial aircraft applications, [11]. It integrated three different morphing systems on a $5.5 \mathrm{~m}$ span demonstrator, positioned at the leading and trailing edges, and at the winglet, respectively. A NASA/AFRL joint project (Adaptive Compliant Trailing Edge, ACTE) involving Gulfstream and Flexsys, designed and tested in flight a compliant adaptive flap prototype aimed at replacing all the conventional control surfaces on the wing, [12]. Experiments were carried out in 2014 and gave full demonstration of the capability and potentiality of the envisaged technology. Many other studies have been carried out since then, like [13]; currently, AG2, a large European project within the Clean Sky 2 Green Regional Aircraft program, aims at the full-scale, functional flight testing of an adaptive winglet, in 2022, [14]. This list is not exhaustive at all, being necessary a devoted paper to deal and discuss the recent developments of morphing wing technology, but the cited examples are believed enough to understand how far the research has gone.

Coming to full manned aircraft, both civil and military, it may be of a certain interest to recall actual flying systems, flown onboard of very famous planes like the Concorde (droop fuselage nose) or the F-14 (variable sweep angle), [15]-[16]. Other existing static systems are the aircraft current stored on a typical air-carrier, that needs to fold their wings, or tilt rotor vehicles that use to orientate differently their rotors (and the hosting lift-generating supports) as a function of the flight phases. For the sake of completeness, it should be also considered that morphing devices, even if very far away from a smart structure architecture, have always been employed on airplanes: flaps, slats, ailerons, rudder are necessary to fly. No aircraft could face even the most elementary flight phases demand without adaptive capabilities. Standing then the remarkable knowledge developed over the years on deformable wing shapes, and the consolidated technology that allows even complicated systems to fly while respecting the demanding regulations, it is almost natural to wonder why such idea has not yet being implemented on real aircraft. 
It is about 20 years that a revolutionary morphing wing concept was introduced by Northrop-Grumman within the DARPA-sponsored Adaptive Wing project, (1997-2002), where a completely embedded and continuous system was developed and tested, even if in the limited environment of a wind tunnel and mounted on a UCAV, [17]. What showstoppers have slowed down the technology development, and how far is the engineering from the actual implementation of that vision? As it often happens, there is not a unique answer. Instead, there is a concurrency of reasons that span from the purely technical point of view to the need to properly accomplish the existing regulations while keeping low operational costs and high safety levels. It may be that an important item like aeroelasticity enters in one or more of the listed reasons; however, it is preferred to deal with it separately since it may represent an issue usually neglected, while it should be instead duly taken in account. New, breakthrough technologies lead to new aircraft configurations and new design approaches. As a consequence, it shall be expected that new methodologies and design processes are needed to better tackle the new outline of the vehicle system, and its mutated complexity. However, assessed procedures required time, and it is almost physiological that a time shift occurs between the rising of a new technology and the set-up of adequate design means. This fact inevitably leads to a limited estimation of the complete effects of the innovation on the comprehensive performance, affecting the vehicle's assessment along its whole lifecycle. On the other hand, it should be recognized that the future perspective of a more and more electric aircraft could be a facilitator of morphing on the aircraft of the next generation. The wide presence of cabling and connections will make it easier to design an extensively broad network of actuators and sensors, which are supposed to be the core part of the system. Cabling design, the choice of a distributed or centralized power supply architecture, and the influence of the induced magnetic fields will be one of the key aspects of the electric craft. The further presence of morphing systems could be one of the key aspects to consider before coming to a final choice.

In this paper, the authors try to list the weak points of the chain and how they can be overcome to guarantee the installation of morphing systems onboard of commercial aircraft. The identification of the class of vehicles is essential for the abovementioned scalability issues, but even for the very different requirements and expectations that the various airplane classes could arise. The variety itself of the difficulties makes it necessary to articulate such a survey properly. Technical aspects will be faced first; design issues will follow; finally, operational and implementation aspects will conclude the analysis. This paper is not meant to be an exhaustive vision on morphing technology, which instead would certainly require volumes and volumes. It simply aims at moving some questions on the latest developments and, hopefully, stimulate a different focus on topics sometimes neglected.

\section{Preliminary Considerations}

Before going into details, some fundamental reflections shall be carried out to properly introduce the following concepts.

There is no special concern of the existing regulations about the use of morphing systems. Even the most revolutionary of those ones is based on accessible and well-assessed technology, or clear ideas. It is instead the exasperation of the proposed concepts and the novelty according to which they are arranged together that raises the challenge. For instance, the most popular architectures that de facto divide the scientific and technology community in two parts, are based on kinematic systems and compliant structures. Both of them are largely present on commercial aircraft, even if at a smaller extent, than it would be needed for a fully morphing system.

As by now, there are two major architectures including any kind of morphing solutions: kinematics, like the one proposed in SARISTU, or compliant, as the one proposed in ACTE. In spite an accurate analysis would show the large similarity of the two concepts, with some and confined strong exceptions (like the design of the load-bearing frame and 
the realization of the lability elements, allowing the movement), the discussion concerning their limitations and perspectives would be very different. Therefore, the authors decided to focus on kinematic systems herein, shifting a larger dissertation to a next work, which presumably will take advantage of the conclusions that will be drawn here.

\section{Technical Aspects}

The core of any morphing system is composed of a structural skeleton, sensor and actuator networks, a control system, and an enveloping skin. Following, the single elements will be recalled, and their major weakness points will be highlighted. Such topics will be finally summarized in a table for an immediate understanding and transferring of the result of this analysis.

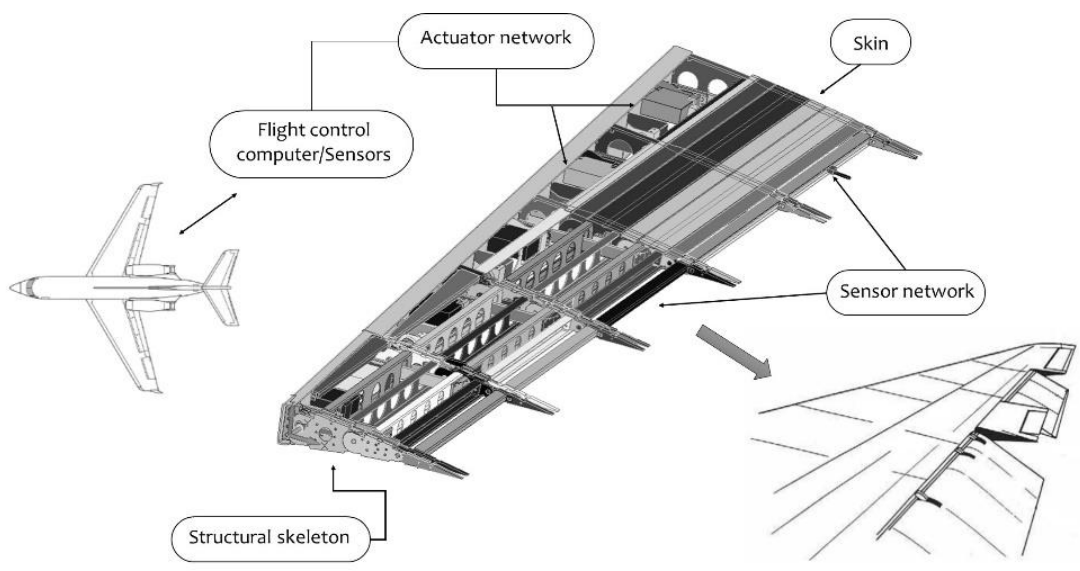

Figure 1. Schematics of the morphing wing device subsystems.

\subsection{Structural Skeleton}

The structural skeleton is the part of the system enabling the change of shape and withstanding the loads related to all the configurations it can be morphed into. Therefore, its design needs to combine adequate compliance to efficiently accommodate large shape changes and enough stiffness to counteract external loads with proper margins of safety.

Three different structural solutions may be adopted to comply with this requirement:

- Articulated mechanism: the skeleton is composed of structural elements interconnected by hinges and leverages and arranged into a mechanism with one or more degrees of freedom. As a mechanism, the skeleton cannot withstand external loads if its degrees of freedom are active.

In this case, the actuation chain plays a crucial role as it works along the active degrees of freedom to change the shape of the skeleton and adsorbs part of the external loads while constraining its movements.

- Compliant structure: the structure is a rational assembly of subcomponents with no active degrees of freedom. The actuation chain induces elastic deformations of one or more subcomponents to morph the skeleton according to the desired shape. In this case, the actuators have a less significant role in withstanding the external loads as the skeleton has an intrinsic (and tailored) stiffness. However, this does not mean reduced demand for actuation power since the actuators must counteract the stiffness of the structure to morph its shape,

- Hybrid structure: combination of the two structural solutions listed above.

Irrespectively of the adopted structural solution, the skeleton cannot be seen as a critical path, as long as it is concerned with standard parts and the usual way of assembly. This is even more true if the articulated mechanisms are addressed. Of course, it should be noted that the number of elements may increase significantly with the number of shapes the skeleton can assume Such a number is associated to the number of degrees of 
freedom that the system needs to be given as a function of the targeted performance of the adaptive architecture. Connected to that, the number of interfaces grows as well, and that fact further increases complexity. This aspect also involves the number of connections and, therefore, the joints in turn associated with a non-neglectable boost of weight.

\subsection{Sensors}

As for the structure, sensor networks cannot be seen as a major criticality, in principle. There are many certified devices in commerce, suitable for aircraft applications (civil or military); therefore, the access to that technology is not a matter of concern. However, again linked to the number of degrees of freedom that the structure wants to be given, the number of necessary sensors also grows. This fact has at least two major impacts: the number of cables may explode, involving room and weight necessity: devices number may significantly expand, luckily with no direct impact on room and weight penalties. Both those issues give however rise to an increase of architectural complexity.

\subsection{Actuators}

Again, a distributed degree-of-freedoms system, does necessarily require a certain number of actuators to work properly. The alternative is to reduce the number of motors but increasing the mechanical system ramifications to distribute unequally and in a controlled way, the actuator action. In that case, the number of active devices would anyway increase, shifting the needs of adequately commanding a certain line to mechanical switch, in turn consisting of micro-actuators and a further increased complexity of the system architecture, with increased cabling, either.

Since a distributed system cannot be based on hydraulic or pneumatic actuators for reasons of accessible room and weight, the use of electromechanical actuators (EMA) is almost mandatory. Even though this kind of device is studied in many research projects worldwide, many aspects regarding reliability and certification are still open. In fact, in order a proper morphing system is realized, actuator shall be small enough to fit the structural body while guaranteeing the necessary level of forces. A certain number of devices is accessible on the market, but many of them suffer export limitations so that technology cannot be marked as "mature". Furthermore, because many of them have been developed for the military UAV market, some civil certification requirements could not be satisfied,

A significant issue concerning the actuators is the need to take them as a part of the structural system. In fact, because the skeleton shall allow lability in order to be moved, it follows that the actuator shall bear part of the load (if it is removed, the system is a mechanism with unconstrained degrees of freedom). Therefore, the actuator shall usually concur to sustain external and internal loads. Since the aircraft is an isolated system, the force absorbed by the actuator is transferred to the structure through the connection interfaces. The connection of the motors to the structure (usually the main spar, with the attachment deployed on its web), shall be re-designed to consider that unusual load.

\subsection{Control System}

Conformally to the structural skeleton and the sensor network, control systems have been widely used on all types of aircraft, civil and military, manned and unmanned, models or real-size. Therefore, technology accessibility is not an issue. However, what it does change with morphing systems is the number of variables to be controlled, in turn linked again to the targeted DOF. The number of variables may affect the control algorithm complexity, the control system stability and, as a consequence, certification. The process may terminate in a reduction of the operational envelop and the resulting architecture could be heavily resized as a function of the imposed constraints.

In the case of control systems, the requested functions also have an impact on it. Many operations could require a complex analysis of the internal and external variables, while ensuring the whole machine is stable and works properly. It may be argued that robotics has dealt with and partially solved this kind of problems for a long time; the easy 
answer is that the environmental conditions are very different from a quasi-static, ground analysis.

\subsection{Skin}

This is perhaps the most critical element in the set-up of an adaptive wing. It is also the sole element, among the cited ones, whose criticality is not driven from the degrees of freedom. It has to behave in a certain way independently of how many movements shall be realized. Instead, it depends on the extension of the envisaged deployment.

The key of a morphing skin functionality is its capability of being extended for deformations that can attain $10 \%$ with a minimum amount of forces while guaranteeing high transversal stiffness. The first property follows the necessity of limiting the effort required to the actuators, while the second one derives from the need to preserve geometrical continuity under the action of aerodynamics that could otherwise generate irregularity in the wing outline. Since the most obvious solution to the excess of deformability is the increase of thickness, weight and accessible volume is consequently affected, with severe impacts on the overall system economy. Unfortunately, if not well addressed, this augmented stiffness also causes a degradation of the performance in the other directions, leading to added loads to the actuator system.

All mentioned subsystems (structure, sensors, actuators, logic, skins) present an additional problem: the problematic scalability, here intended as the transportability of the technology from a class of vehicle to another one. This aspect cannot be always addressed just by scaling the subsystems, since their performance does not follow the geometrical scaling factor. To cite some example, hydraulic actuators suited for large scale applications cannot be miniaturized over a certain level and must be substituted by more compact actuators. A structure conceived to change the chamber of a wing of a small UAV, cannot be resized to fit larger classes of vehicles since its flexibility would be dramatically altered, up to result too rigid, and a system originally compliant could be converted into a kinematic chain. For this reason, designers are often forced to dramatically change the structure layout, the type of sensors and actuators, and the physical principle at their basis.

Table 1. Summary of weakness and criticalities of a Morphing System - Components.

\begin{tabular}{|c|c|c|c|}
\hline Components & Origin & Weakness & Impact \\
\hline Structural Skeleton & DOF given & $\begin{array}{l}\text { Number of parts } \\
\text { Numb. of interfaces } \\
\text { Number of joints }\end{array}$ & $\begin{array}{l}\text { Complexity } \\
\text { Weight }\end{array}$ \\
\hline Sensor Network & DOF given & $\begin{array}{c}\text { Cabling } \\
\text { Number of devices }\end{array}$ & $\begin{array}{c}\text { Complexity } \\
\text { Weight } \\
\text { Volume }\end{array}$ \\
\hline Actuator Network & $\begin{array}{c}\text { DOF given } \\
\text { Room available } \\
\text { Specifications }\end{array}$ & $\begin{array}{c}\text { Number of devices } \\
\text { Cabling } \\
\text { Reliability } \\
\text { Availability }\end{array}$ & $\begin{array}{c}\text { Complexity } \\
\text { Weight } \\
\text { Volume } \\
\text { Technology access }\end{array}$ \\
\hline Control System & $\begin{array}{c}\text { DOF given } \\
\text { Requested functions }\end{array}$ & Stability & Complexity \\
\hline Skin & $\begin{array}{l}\text { Displacement } \\
\text { targeted }\end{array}$ & $\begin{array}{c}\text { Availability } \\
\text { Fatigue resistance } \\
\text { General deformability } \\
\text { Type and numb. of } \\
\text { joints }\end{array}$ & $\begin{array}{c}\text { Shape degradation } \\
\text { Weight } \\
\text { Volume }\end{array}$ \\
\hline
\end{tabular}

\section{Design Issues}

\subsection{Approach}


Even though the adaptive structures herein referred are an evolutionary concept of the existing systems, it is undoubtful that there are significant impacts on the design process. In fact, the skeleton is made no more as a single block with a certain shape whose changes under the aerodynamic and internal load could be eventually taken into consideration. Here we have a bundle of structures that should be separately verified under the presence of the prescribed excitations. For instance, if a droop nose is referred, whose geometry may change between 0 and $20 \mathrm{deg}$ (inclination of the mean with respect to the nominal chord), the system should be verified tested for different configurations. This aspect arises a first issue: how many steps shall be considered? (1, 2, 5 deg? Or even less?). The answer severely impacts the operation to assess the established design.

Even if this topic has been rarely considered till now, maybe the necessity of referring to a "zero" shape shall be considered. This issue has not been emphasized until now because the larger part of the studies refers to existing aircraft, whose capability has been augmented by the insertion of adaptive parts. Therefore, the basic geometry was intrinsically defined; what will be the impact of imagining a morphable aircraft with variable shape along with its life and its mission; what will be the choice of the designer? While it may be easy for commercial aircraft to indicate the cruise condition as the reference one, this item may be dramatic for military or UAV platforms.

An immediate consequence of this consideration concerns the specification's issue. How the customer or the design staff (aiming, for instance, at placing a novel aircraft on the market, with new and interesting features) will measure the envisaged requirements? In this case, the lack of tradition and consolidated process plays an important role. This is perhaps the most critical aspect: without assessed indications, there is the risk of an indefinite time for producing the final schematic and several iterations with the specs generator before a shared vision is set- up.

Another important aspect is represented by the highly integrated level of the different components of a morphing system. This aspect, crucial for the correct functioning, has a dramatic impact on the design approach. With specific reference to the structure of a drop nose system, it is ideally possible to distinguish between main subparts as the internal structure that transmits deformation from the actuator to the skin, and the skin itself, that must assure a specific shape and distribute the external load to the interior parts. It is evident that, despite to this distinction, it is not possible to face the design of the components separately. To further extend this reasoning, we can imagine that these components are made of different materials, for instance a multilayer hybrid skin (outer part of soft elastomeric material, inner part of honeycomb), connected to an interior supporting structure, made of a super-elastic alloy. The design approach must rely either upon a unique multiphysics tool or a shell open source software, that can handle different specific tools.

Still, with reference to the high integration level, structures actuated through shape memory alloys (SMA) active parts present a further complication: the pre-load. Since the exploitability of a SMA actuator is strictly related to the martensite phase concentration, in turn produced by the pre-load level, the surrounding structure shall withstand the conventional loads and also produce an adequate stress level within the SMA. This evidently leads the structure to work in an unconventional way, characterized by a generally higher stress level.

\subsection{Tools}

Something that runs in parallel with the design approach is related to the available tools. Usually, they refer to structural systems, while recently many proprietary tools have been developed to consider the aerodynamic loads to assess the target wing shape. In fact, since the aerodynamic characteristics of a body are a consequence of its shape, the deformed configuration is essential to guarantee the envisaged performances. This non-trivial approach complicates a lot as new DOF are added, whose activation depends by a number of kinematic architectures and electromechanical actuation systems. The targeted simulator shall not only consider the presence of such complex systems, but it has to 
correctly simulate the presence of the structural elements allowing displacements (hinges, gears, and so on).

Some researchers have recently demonstrated the impact of rotational and translational constraints on the simulated structural response, which can drastically affect the final result. In this context it is no more sufficient to have at disposal FE codes, combined with aerodynamics and enriched with multi-body capabilities. Detailed simulation of particulars is requested. The easy criticism to this statement is that, after all, the prospected kinematics, is not that different by the current flaps and ailerons, for instance. The answer is yes, of course. What it does change however, is the number of these components spread all over the aircraft. Instead, since the presence of many discontinuities linked to the distributed kinematics arises, it is expected that the number of singularities will explode in the analysis, in turn requesting deeper investigations. Again, this impacts the time and costs of the design process.

Complementarily, the use of tools for issuing appropriate load conditions is affected. Again, a bundle of geometries shall be considered, together with many local imperfections. Either, since the structure is interrupted by many discontinuities, the usual way to provide the internal solicitation characteristic may be affected by some forced assumption that should be necessarily removed to avoid excessive conservativisms.

\subsection{Aeroelasticity}

This part of the design is treated separately for its sound peculiarity. It refers to the analysis of the interactions between inertial, elastic, and aerodynamic forces arising on the structure when it moves in the airstream. If inertial forces are neglected, the static behavior of the system can be investigated by referring to the previously outlined concepts, concerning tools and approaches. In the case of relevant inertial forces (high speed/accelerations), the dynamic stability of the system becomes a crucial design aspect, and flutter analysis is required since the preliminary design stage of the adaptive structure. It is already expected that the system, having augmented DOFs, will have a more complex aeroelastic response in terms of modes involved in potentially unstable coupling mechanisms. This is closely linked to the characteristics of the many systems composing the morphing aircraft as the combination of structural parts, kinematic architectures, and actuation devices. Their integrated response deserves great attention from the modeling point of view. Since the system is generally characterized by largely distributed characteristics, its dynamic condensation cannot follow the standard approaches, and the resulting output shall necessarily be made of a considerable number of grids, elements, and properties. Considering that the aeroelastic evaluation shall be carried out on the complete aircraft, this situation leads naturally to complex models, whose analysis is not trivial and presumably deserves many iterations to be finally assessed.

Once more, the main question is concerned with the discretization that shall be implemented to ensure a correct outcome. In other words, given the geometrical domain that represents the possible configurations the morphing aircraft may assume, what is the step that can be considered sufficient to explore it? There is not a standard answer yet, neither a shared criterion for defining it. A practical approach would be to adopt specific solutions to overcome potential instabilities detected along with the study. The installation of balancing masses is among the most effective solution to fix aeroelastic issues with minimal impact on the consolidated design of the item. Nevertheless, because different configurations shall be explored, there is no guarantee that a practical solution working for a given configuration is also effective for the others. The problem is again associated to the introduction of suitable tools that can consider any possible issue for any possible configuration before and not after it has been detected.

\subsection{Coupling}

A rarely treated topic concerns the cross interactions of the different morphing systems that can be deployed over the wing or the whole aircraft in general. In fact, since the 
aircraft is an isolated system, the stresses and strains generated by the action of a single adaptive device transmit along the whole structure and may give rise to unwanted or at least unpredicted deformations. It may be perhaps assumed, with a certain level of confidence, that a morphing rudder cannot induce aileron deformations, to a certain extent, but this hypothesis cannot be held anymore if different wing components are referred to, as flaps and slats. This phenomenon has been reported in the literature and simply means that a morphing aircraft cannot be, at least in principle, designed by parts but should be approached as a whole, since the first time. Again, the associated difficulty is linked to the available tools and the lack of a significant background experience in dealing with this kind of problem extensively. It is worth mentioning that many hints may be taken from the movables currently being mounted on a generic aircraft, but the larger density of adaptive systems would require different attention on the specific thematic.

\subsection{Preexisting subsystems}

When developing a morphing system, generally two scenarios appear to the designers: the aircraft is completely new and the general layout can be defined ex-novo, as the morphing system; the aircraft already exists, its architecture is well consolidated and the morphing devices must replace some conventional subsystem.

Generally, this second option is the most common, and the designers must meet requirements strictly related to the preexisting layout. Especially in this case, the impact of the novel morphing system plays a critical role. Needed energy, structural connections, working modality must be accurately weighted to minimize the impact of the novel system onto the rest of the aircraft and avoid any undesired penalization due to the overlapping of the pre-installed technologies.

To cite an example, for the specific case of an adaptive chamber flap or a drop nose, the designers will face the problem of ideally removing the conventional subsystems and related actuation layouts and replace them with the novel architectures, whose connection to the wing box and whose allocation of the actuation subsystems are really different and, especially for compliant mechanisms, implies a specific load transmission path to the wing box. The total weight (here intended as the sum of the morphing systems themselves and the wing structure) from one side cannot be compared to the weight of the replaced conventional devices, since these do not include the kinematic chain and the actuation systems, but from the other side must be limited as much as possible to not undermine the benefit expected by the new technologies.

Another example is represented by a morphing leading edge's impact on conventional preinstalled ice protection systems. These systems (hydraulic, pneumatic, electromechanics, thermal) are conceived to act onto rigid structures: part of them are supported by the interior structure and by the skin. If the surrounding structure morphs, the problem of the stability from one side and of the effectiveness from the other side, arises. In this case, the introduction of a morphing device cannot be faced separately from the integration of other subsystems or from the attempt of including some additional functionality (ice removal) in the morphing device itself.

Table 2. Summary of weakness and criticalities of a Morphing System - Design.

\begin{tabular}{c|c|l|l}
\hline Step & Origin & \multicolumn{1}{c}{ Weakness } & \multicolumn{1}{c}{ Impact } \\
\hline Approach & DOF given & $\begin{array}{l}\text { Number of configura- } \\
\text { tions }\end{array}$ & $\begin{array}{l}\text { Time-to-assess } \\
\text { Specifications issue }\end{array}$ \\
\hline Tools & DOF given & $\begin{array}{l}\text { Number of joints } \\
\text { Lack of comprehensive }\end{array}$ & $\begin{array}{l}\text { Deformability under } \\
\text { Analysis of singularities }\end{array}$ \\
& & tools of outdated methods & Sime-to-assess \\
& & & Simulation confidence \\
\hline
\end{tabular}




\begin{tabular}{|c|c|c|c|}
\hline & & & $\begin{array}{l}\text { Excessive conserva- } \\
\text { tivisms }\end{array}$ \\
\hline Aeroelasticity & $\begin{array}{l}\text { DOF given } \\
\text { Geometry domain } \\
\text { given }\end{array}$ & $\begin{array}{l}\text { Number of configura- } \\
\text { tions }\end{array}$ & $\begin{array}{l}\text { Time-to-assess } \\
\text { Balance complication } \\
\text { Aeroelastic model size }\end{array}$ \\
\hline Coupling & $\begin{array}{c}\text { Number and location } \\
\text { of morphing systems } \\
\text { deployed }\end{array}$ & Interaction phenomena & $\begin{array}{l}\text { Iterations } \\
\text { Performance unpredicta- } \\
\text { bility } \\
\text { Overall aircraft simula- } \\
\text { tion }\end{array}$ \\
\hline
\end{tabular}

\section{Manufacturing and Assembly}

\subsection{Manufacturing}

The manufacturing represents one of the most challenging aspects of the development path of a morphing system. The possible use of unconventional materials like hybrid metallic-ceramic components and smart materials may further complicate the scenario. Such peculiar components may require specific processes, as the sintering of piezoelectric powders, [18], or suited melting and milling processes for shape memory alloys, [19]. Topology and chemistry of variable stiffness parts may be very complex, hardly compatible with conventional manufacturing processes (milling, melting, bonding). Coexistence of more materials, each with its own characteristics, implies engineering concurrency and a multidisciplinary approach.

The most relevant concern is associated to the number of parts, which can be very relevant. In fact, the architectures of the morphing device and the hosting structure require necessarily to suit each applicable section, resulting in different elements at the various positions, directly affecting the layout of the kinematic systems. A rationalization of the subsystems outline is usually necessary, including actuator and sensor networks, with potential impacts on the effectiveness of the guidance logic.

Since the production process needs a maturation involving setting and optimization of the concurrent parameters and the demonstration of the reproducibility within certain levels, many questions arise, related to the need of a maturation period for the related industrial processes.

\subsection{Assembly}

The assembly process of an integrated morphing system is generally different and more complex than conventional ones, featuring the embedding of the whole components with the aim of producing clean surfaces. Even though -from a traditional point of viewit is still convenient to distinguish among logic, sensors, actuators, structure, and skin, it results that system efficiency is strongly related to their amalgamation level. This directly impacts the design process, of course, as anticipated in the previous section, and has even an impressive influence on the assembly process.

To cite some examples, a morphing structure may require a certain level of pre-load, needed to assure the correct working condition of SMA actuators if present, [20]. This needs in turn dedicated processes and devoted rigs, jigs ad tools for imposing the envisaged stress, while putting together the multitude of system components. Another example regards the installation of sensor networks that become an intimate part of the structural components, with the associated cabling and electronics. Their interface may be critical for the correct functioning of the whole system, [21]. The same applies for actuation systems that in this case also have the important role of load-bearing elements, with relevant consequences on the structural integration.

Increased DOFs imply the multiplication of interfaces; multi-component architectures may be hard to handle and require specific tools; non-homogeneous material composition must be carefully treated during handling and fixing operations to avoid 
inappropriate solicitations and fracture onset. Other topics that may arise relate to possible junctions of adaptive with classical materials like SMA in composite materials, [22], or piezo transducers within elastic components, [23].

Strictly related to a morphing system efficiency, assembly processes shall mitigate undesired free-play and gaps within kinematics. In this wake, the most peculiar aspect of adaptive with respect to classical systems shall be cited, based on their intrinsic nature. The increased DOF and the necessary lability until the actuation system is integrated and blocked make the structure movable during the integration. There is no more a static configuration that grows rigidly step by step, but is instead the creation of a chain with multiple capabilities of movement. Apart the clear general difficulty, the need of dedicated jigs and tools is evident, to limit the displacement at the most even during the most common processes for standard structures (drilling, riveting, bolting, and so on). This simple consideration may have tremendous consequences on the production time and costs.

It should not be neglected the presence of uncommon materials even for apparently usual components, like the skin. The necessity of having large strains with minimal stress penalties, directly impacting the actuation system performance, naturally brings towards elastomeric solutions, with all the limitations that have been recalled. These materials however, have critical issues with respect to traditional assembly methods. Elastomers are hard to be drilled and riveting may be hard to be used to join related arts.

A last consideration regards the current scenario. The current industrial trends aim at simplifying building procedures for minimizing times and costs. The introduction of a morphing system is certainly conflictual with those tendencies.

Table 3. Summary of weakness and criticalities of a Morphing System - Manufacturing \& Assembly.

\begin{tabular}{|c|c|c|c|}
\hline Step & Origin & Weakness & Impact \\
\hline Manufacture & $\begin{array}{l}\text { Increased DOF } \\
\text { Unconventional materi- } \\
\text { als } \\
\text { Conformal geometry }\end{array}$ & $\begin{array}{l}\text { Many different parts } \\
\text { Reduced size of many } \\
\text { parts } \\
\text { Needs of suited processes } \\
\text { Needs of precision pro- } \\
\text { cesses }\end{array}$ & $\begin{array}{l}\text { Time of manufacturing } \\
\text { Creation of specific tools } \\
\text { Production chain en- } \\
\text { largement } \\
\text { Quality tests increase } \\
\text { Tolerance reduction }\end{array}$ \\
\hline Assembly & $\begin{array}{l}\text { Increased DOF } \\
\text { Pre-loaded components } \\
\text { Load-bearing actuators } \\
\text { Integrated sensors }\end{array}$ & $\begin{array}{l}\text { Labile sub-structures } \\
\text { Hard handling procedures } \\
\text { Unconventional integra- } \\
\text { tion process Interface in- } \\
\text { crease }\end{array}$ & $\begin{array}{l}\text { Dedicated jigs and tools } \\
\text { Novel processes } \\
\text { Evolution of standard } \\
\text { processes } \\
\text { Time of assembly }\end{array}$ \\
\hline
\end{tabular}

\subsection{Ground testing}

The ground testing of the assembled morphing component is a fundamental task that is generally required before its final integration into the aircraft, especially when dealing with prototypal architectures.

The primary purpose of the tests is to prove that the structure can safely withstand the most severe loads expected in service (static tests) and that the system is morphable in compliance with the required morphed shapes (functionality tests). Resonance tests can also be carried out for some specific components to validate the dynamic models developed during the design phase.

Unlike conventional structures, morphing systems demand the tests of different configurations along with several sets of loads.

Therefore, pre-test simulations are highly recommended to rationally define a limited number of test conditions enveloping the most relevant combinations of configurations and loads. Once the enveloping conditions are determined, the following general procedure can be followed for each condition: 
a. Functionality test: the test article is morphed and unmorphed repeatedly by activating the actuators through the control system. During this process, the external shapes of the test article are acquired (by 3D scan or displacements' measurements at a set of control points) and compared with target ones. The outcomes of this comparison provide a means of evaluation for the reliability and the robustness of the system's functionality.

b. Static test: The test is carried out to prove that the structural system is able to withstand loads without detrimental deformation or failure. A careful installation of the whiffle tree has to be carried out to apply operative loads without constraining the natural degrees of freedom of the morphing system; for instance, in the case of the segmented articulated ribs (as those shown in figure 1), segmented load saddles must be used to not prevent the relative rotation of rib blocks). The natural degrees of freedom of the structure must be constrained only by the actuators (in power-on mode) and related transmission lines; the entire actuation chain is therefore a relevant part of the test article and must be sensorized to get info on load-induced strain and elastic displacements. In addition, the power adsorbed by the actuators to maintain the shape of the loaded structure must be measured to ensure that the actuators still possess enough authority to morph the system in operative conditions.

c. Functionality check: after unloading the test article, the functionality tests are repeated to check that the stresses/strain fields arisen during the static test and the level of power adsorbed by the actuators to counteract the external loads, have not compromised the morphing performances of the system.

\section{Operations}

\subsection{Maintenance and Repair}

Maintenance and repair operations have a significant impact on running costs and thus on market attractiveness as well as flight safety [24]. A morphing system disregarding this aspect risks to nullify the benefits produced in terms of performance and environmental impact.

The time needed by maintenance operation is the most critical aspect since it directly influences the usage time of the aircraft. Thus, attention is paid to the effectiveness of the procedures and on the reliability of the interventions, as well as to their compliance with the current regulations.

A morphing system poses different issues, strictly related to the nonconventional architectures often hardly to inspect, the presence of non-conventional materials with not enough studies supporting life cycle and reliability, sensorial architectures non-conventional themselves and also subjected to new logic of monitoring, sophisticated logics of control suited for multi-distributed DOF systems. However, more than anything, the deep level of integration of a morphing system represents itself a criticality from the maintenance point of view [25].

When introducing a new concept onboard the aircraft, the impact on maintenance procedures and operations is one of the most relevant information that should be provided in order to understand if and to what extent the benefits of the technology are real. A dedicated analysis is then necessary. A maximum allowable time period shall be established before a maintenance action is required for announced failures. Latent failure will be managed by a scheduled maintenance task. If this approach is taken, component Mean Time Between Failures (MTBF) is the basis for establishing the check interval time, e.g. time intervals between maintenance and operational checks/ inspections.

Standing the basic hypotheses of this work, kinematic systems and electromechanical motors are referred to. Sensor networks are not so different from the usual systems, currently used while control system software follows the same rule. Where available, service history of similar or same components in a similar or the same environment should be used. Impact of new materials shall be duly considered. 
As a basic consideration, it can be said that a maintenance plan can be prepared on the basis of the existing experience on the different items. However, some differences arise. Generally speaking, the integration of the components makes it hard to deal with them separately; this aspect has an important fall-out on the repair process.

Repair operations are in practice affected by the lack of knowledge on the new materials involved that determines uncertainty on the type and effectiveness of the repair action. Damage on monolithic or quasi monolithic structures must be adequately handled, from one side, to avoid the substitution of the entire component, but must be also properly secured in compliance to the specific unconventional working modality of the part. Also, repairing a distributed sensorial system may require invasive operations, often non-localized on specific parts, but involving the entire network.

Starting from motors, even with the assumption of having excellent life expectations, the simple fact to have a large number of such devices imposes to reduce the inspection times by a figure inversely proportional to the implemented systems. The same applies to kinematic architectures and related components. Since these elements are commonly used and treated, no special attention shall be paid on them.

Embedding sensors in the structural components generate some issues. Apart from the obvious difficulty of detecting the faulting device in a large and distributed array, the presence of malfunctioning in an integrated net lead to the necessity of dismissing the whole segment. In turn, this fact generates the need of a suitable design of the interfaces connecting the different channels, so that cabling shall not be revolutionized by such a substitution. Also, if the system has the goal of providing critical information on system faults, it should be designed to maximize its maintainability by allowing, for instance, quick, easy and safe access for repair or replacement or by preventing inappropriate connections or interpretations.

While structural parts and software dedicated to system guidance are definitely standard parts whose maintenance procedures are well coded and assessed, something different concerns the skin, if elastomeric-based solutions are addressed. This kind of material is particularly sensible to the external conditions and suffer the action of the environmental agents, and is not reparable. Definitely, this aspect could be overcome by novel attainments in the material sector, but that is the situation right now. So, damage on such surfaces, essential to preserve the geometry, cannot but lead to the substitution of the entire segment.

The presence of a large number of parts, all different the ones from the other, brings added complexity to the problem. A suitable repair process shall necessarily rely on a number of accessible spare parts, with significant impact on stock sizes and cost. These reflections translate into specs for the design that shall duly consider the interfaces, the access to the different elements, and the issues for repair and substitutions. It is almost obvious that a complete re-styling of the procedures is useful for the augmented complexity of the system, in spite many elements are still traditional.

The challenges of maintenance of morphing structures could be summarized in just a couple of questions: how can the lack of knowledge on new materials, systems, and configurations be handled to obtain a final product competitive also from the maintenance point of view? And how can regulation update fill the gap with industrial applications?

\subsection{Safety}

To comply with the EASA CS-25 requirements considering both operational implications and crew work load, a morphing wing device, as any other equipment and systems installed onboard aircraft, shall be designed and installed so that any catastrophic failure is extremely improbable and does not result from a single event. The entire system or the individual subsystems must be substantiated by analysis and tests in airplane or in a mock-up installation to determine proper performance and prevent failures. This is generally guaranteed by: adequate design avoiding stress concentration, instability, corrosion; a dedicated logic of control to prevent dangerous conditions and mitigate the load 
distribution; a monitoring system able to sense the current status of the architecture. All these aspects are, however, very challenging: designing a structure flexible and rigid at the same time means to handle the stress and load distribution beyond conventional schemes; logics of control able to handle more DOFs than usual must exhibit higher performance and a higher rate of affordability; health monitoring systems suited for the early detection, the quantification of the damage and supported by a logic to mitigate the effects due to the damaging.

Novel aircraft functions associated with adaptive systems impose the introduction of new fault trees for catching the associated risks at level of the complete airplane. Before conducting a detailed safety assessment, a Functional Hazard Assessment (FHA) of the airplane shall be prepared by considering the potential failures of airplane level functions due to the system's malfunctions. This phase is concerned with the operational vulnerabilities of the system rather than with a detailed analysis of the actual implementation.

An inverse relationship is commonly accepted between the average probability of fault occurrence per flight hour and the severity of its effects. Catastrophic failures must be extremely improbable and must not result from a single failure; extremely improbable failure conditions are usually considered as those having an average probability per flight hour of the order of 1e-9, depending on the specific systems. Quantitative probability terms are also set to hazardous failure conditions that must be extremely remote (average probability of $1 \mathrm{e}-7$ per flight hour), and major failure conditions that must be no more frequent than remote (average probability of 1e-5 per flight hour).

Safety assessment consists of three phases, moving from the single devices or subsystems to the whole aircraft, as cross-effects and interactions are studied, including the influence of software and human interfaces.

Safety aspects are once more correlated to the number of parts and components. The reliability of $\mathrm{N}$ components is $1 / \mathrm{N}$ of the reliability of a single component. Therefore, as the system is enlarging in size, the need to increase the reliability of the single element becomes stringent. This applies to all subsystems so that the use of morphing technology imposes the development of safer elements by several magnitudes. This can be a critical aspect of the realization process. A simple statement regards in fact the evolution of the aircraft market. It is something that was generated before the COVID emergency, but it is a shared opinion that, after a contraction of the demand, former trend will be restored. If we think to a factor $10 x$ of growth along a certain historical period, to maintain the absolute accident occurrence at the same level, the mean failure probability of the aircraft component shall decrease by the same quantity, i.e. arriving to $1 \mathrm{e}-10,1 \mathrm{e}-11$, figures that pose an extreme challenge to technology. The introduction of morphing systems, their complexity, together with their larger number of parts, would decrease those numbers even more.

Additionally, specific maintenance procedures shall be developed to identify any hazards and ensure the continued airworthiness of the morphing system. In this respect, particular attention should be given to the design aspects to be emphasized in the design process to ensure easy and safe access to the components for fault isolation, replacement, inspection, lubrication. The implementation of an adequate maintenance control program may also contribute to ensuring the structural integrity of critical components.

Safety aspects may be dealt with the classical instruments of tools and fault trees, therefore there is no need to change from the process point of view. On the other side, that process will be longer and more articulated. Introduction of new systems require novel fault analyses that, in turn, have to be combined with the other system functions. Since combinations exhibit a factorial dependence on that number, it follows that times, complexity, and computational risks arise enormously.

Table 4. Summary of weakness and criticalities of a Morphing System - Operations and Safety.

\begin{tabular}{cccc}
\hline Step & Origin & Weakness & Impact \\
\hline
\end{tabular}




\begin{tabular}{|c|c|c|c|}
\hline $\begin{array}{c}\text { Maintenance } \\
\text { and Repair }\end{array}$ & $\begin{array}{l}\text { Increased number of } \\
\text { parts } \\
\text { Integration of compo- } \\
\text { nents } \\
\text { Unconventional materi- } \\
\text { als }\end{array}$ & $\begin{array}{l}\text { Stock size } \\
\text { Repair difficulty } \\
\text { Increased intervals of in- } \\
\text { spections } \\
\text { Lack of suited processes } \\
\text { Behavior uncertainty }\end{array}$ & $\begin{array}{l}\text { Time of intervention } \\
\text { Increased costs } \\
\text { Additional conserva- } \\
\text { tivisms } \\
\text { Process restyling }\end{array}$ \\
\hline Safety & $\begin{array}{l}\text { Increased number of } \\
\text { parts } \\
\text { Increased number of } \\
\text { subsystems } \\
\text { Unconventional materi- } \\
\text { als }\end{array}$ & $\begin{array}{l}\text { Lack of suited processes } \\
\text { Reliability factors approxi- } \\
\text { mation } \\
\text { Increased interfaces }\end{array}$ & $\begin{array}{l}\text { Complexity of analysis } \\
\text { Additional conserva- } \\
\text { tivisms } \\
\text { Process restyling }\end{array}$ \\
\hline
\end{tabular}

\section{Perspectives}

\subsection{Technology}

In a morphing kinematic structure, structural skeleton and actuation system, intending for that the combination of motors and transmission line to the structure, is something that is separated only in the ideas. Indeed, they form a sole subsystem with the intrinsic capability of moving to attain different shapes and bearing external loads. An evolution that is occurring right now is to integrate the design process of both those elements, this partially innovative approach can lead to a certain decrease of the system complexity and parts, maybe accompanied by a slight reduction of the parts number.

EMA actuators have clear limitations for the use in safety-critical applications. Jamming phenomena often require the redundancy of the system, that cannot be afforded in an already crowded application like morphing. Of course, this solution would involve also cabling and routing impact, with severe consequence for the weight. On the other side, the growing use of such a kind of devices, that can be preferred to hydraulic devices for weight, volume and maintenance aspects gives optimal perspectives for the future.

The drawbacks associated with sensor systems may be overcome by using distributed (fiber optics) or wireless networks, which allows envisaging dramatic reductions of the interfaces, cabling and routing, [26]. A matter of discussion concerns the operation onboard of such systems; in that case, it should be noted that a number of onboard instruments have been lately produced by several firms concerning Fiber Bragg Gratings (FBG) and is correct to think these developments would continue to more sophisticated devices. Wireless networks resolve completely the issue of cabling and routing, but arise the problem of pointing out suitable transmission paths and shall face the consistency of data transmission onboard. Among the different possibilities, graphene-based techniques are worth being cited, [27].

The impact of actuation systems, including the kinematic part (i.e. the link between generated forces and morphing structure) may find some relief in giving a major attention to smart materials-based devices. They would significantly affect the number of parts, allowing reductions in terms of volumes and weight. Of course, this would generate major needs for their development till certification; but this aspect is mitigated if it is considered that more and more actuator systems of that kind have been developing and are currently mounted onboard of missiles and rockets, like pin-pullers, exploiting Shape Memory Alloys (SMA) technology. Such devices are finding more and more applications in several market sectors, including automotive, heavy industry and nuclear power plants. In the aeronautical field, some applications may be found on small UAV [28]-[29]. Recently, Boeing has installed an SMA torque tube within aircraft flight test hardware [30], while NASA tested in flight SMA-actuated foldable wings, [31]. Moving from static to dynamic applications, piezoelectric materials may represent good alternatives to some common solutions, as shown on different class of rotorcraft, [32]-[33]. 
As many times recalled, skins are perhaps the most critical element in a morphing system architecture. There are no many materials on the market responding to the linked necessities, required large strain absorption, low normal and high bending stiffness, durability, and possibly high damping. As large deformations are considered, fatigue issues may be relevant. Many solutions have been proposed, including hybrid metallic skins, auxetic materials, laminated composites, multi-stable composites, and so on [34]-[35]-[36][37]. Hybrid solutions involving elastomeric materials and metallic parts could give interesting answers in terms of protection from external agents and robustness from the structural point of view, while properly modulating rigidity properties.

\subsection{Design}

In spite a kinematic morphing structure refers to assessed design tools and regulation requirements almost entirely, since standard components are generally referred to, some points remain open. For instance, the number of configurations that should be tested to prove the reliability of the developed systems require specific attention by the stakeholders community, and represents an issue not faced yet. It is believed that a smooth transition of morphing systems could be convenient even from this point of view. A possible perspective could be represented by the use of adaptive devices as retrofit to existing aircraft; in this case, a lot of experience could be gained, exportable to many other items. Setup of specifications would be easier, and this can be an important factor if it is considered that so much is still undefined when dealing with adaptive structures. Geometrical extension, shaping capability, achievable benefits are still far from being consolidated features, above all for the lack of experience on the matter.

The assessment of dedicated tools is a matter on which some effort is expected in order to overcome clear lack of numerical tools to deal with adaptive systems. Impressive steps forward were done as tools combining elastic behavior and rigid body motions did appear on the market. Now those tools should be further expanded with the capability of considering large deformations (something different from large displacements) either, including the action of forces that are in turn a function of the achieved geometry, combined with detailed models of the singularity points (hinges, gears, and so on). In the same way, optimization tools that could take into consideration the different shapes seem to be necessary in order to achieve necessary weight reductions. It should be clear that such numerical tool evolution is not just required for morphing systems, but it is something that should be also necessary for ordinary engineering. In fact, as the performance of the vehicle is targeted to increase, the necessity of a better simulation that can consider several aspects till now neglected, becomes mandatory.

The usual way to deal with the presence of singularities, like centers of rotation, is to neglect information concerning stress and strain values provided by the numerical analysis (local values) and proceed with a classical semi-analytical tool for the design of the parts. This argument is something that has in itself great limitations, naturally converting into large safety factors and a de facto obstacle to allow the insertion of novel devices based on innovative or, even worst, revolutionary architectures.

These considerations hold even for aeroelastic simulations, where the behavior of the structure needs to be detailed at the most. The approach should include the many singularities that are in the loop, and allow for realizing multi-configuration optimization that can consider the whole geometrical domain, the adaptive structure is called to operate within. Combined with the former topic, a major challenge of aeroelasticity could be the capability of addressing model reductions that could move well beyond the usual standards. Indeed, pure numerical solutions are possible right now, that however make to lose the physicality of the phenomenon. A suitable combination of enhanced methods, exploitation of the basic mathematics, and tools able to reverse the attained information into physical perspective may be a promising development path.

The most complex problem, which affects all the other themes introduced, concerns the coupling of the different systems. Such a complication is very hard to be considered 
in the design phase. Increasing the stiffness of the so-called fixed part of the aircraft would not improve the situation, leading in itself unaffordable increase of weight. This kind of phenomenon may be dealt with through a complete re-thinking of the interface between adaptive and traditional parts, and the development of design tools able to consider the whole structural system from the beginning. Even in this case, the acquisition of a basic experience by the aircraft designers on the topics would certainly help the development process of these new tools.

\subsection{Manufacturing and Assembly}

The presence of a large number of parts is one of the most penalizing issues in the case of adaptive structural systems. Structural skeleton and actuation system may benefit of new technologies to reduce the number of parts, namely Additive Layer Manufacturing (ALM). In this way, it will be possible to reduce the number of parts, impressively, overcoming a major drawback of kinematic morphing systems. This technique may be also conveniently applied to sensor systems with the ultimate perspective of printing the sensible network either, and generally may help to mitigate the complexity of continuous transition of mechanical and physical features among materials of different origin and characteristics, [38]-[39], including the use of smart materials, [40]. Such a technology is already applied to UAV contributing to merge different materials, [41]-[42].

ALM has many showstoppers currently, moving from the cost of the implemented materials (many patented, and therefore their application is strongly restricted and expensive), and resistance characteristics of the products. On the other hand, it should be recognized that such a technology does allow to realize shapes otherwise impossible or extremely challenging to realize by traditional processes. In an analogous way to what evidenced for morphing, even in this case it is necessary to define the overall lifecycle cost after the implementation of ALM or traditional technology. In spite of that, however, additive layer manufacturing may be the right choice of certain morphing systems or some specific components of theirs. These latter are in fact characterized by a huge quantity of unique pieces that could be unaffordable to produce in series with the classical methods. As an example, a wide actuator networks, deployed on a huge area of the wing could have different needs of room and point layout, different for each location, in turn leading to the needs of parts of different size and even shape. Either, gears, of different size and shape could be easily realized by ALM machines, as any other part needing high values of tolerance and high precision, even avoiding the necessity of a massive number of pieces to warehouse. The model will be directly generated from CAD to the real world, passing through a common 3D printer. Assembly of these parts could be envisaged by expanded versions of the current machines, without using too much fantasy, but remaining in the ordinary evolution path. A gearbox can be easily thought of as produced directly by an augmented ALM printer. This step is essential to come to a proper reduction of the system complexity, managing, and other. Of course, specific steps like feasibility and reliability should be assessed, but, again, this is part of the ordinary development track.

Whatever it is, the use of specific jigs and tools for properly assembling the different parts of an adaptive system is a necessary step. The very specialized applications currently require the design and realization of specific elements, the main objective of which is to properly handle deformable architectures without introducing unrecorded stress and strain that could activate unwanted permanent deformations, moving the system far from the design outline. Along this behavior, it is of certain interest to underline how, being the investigated an adaptive system, possible deviation from the nominal shape (the shape " 0 ", above introduced), can be reset after assembly. As a drawback, such reset occurs at expenses of the nominal excursions that should be then oversized to properly consider that possibility.

Off-line subsystems integration may give some further benefit. It is intended to separate the different parts for homogeneity and proceed separately with their integration. For instance, the sensor system may be integrated for each structural element that needs 
it onboard, opportunely designing component interfaces. Integration of actuation and structural systems has already been discussed. This strategy would be paid by a larger assembly time (a new step is introduced), but the assembly process would enjoy more simplicity and robustness.

A separate item deserves the skin manufacture. As by now, skin is seen as a separate part that is added to the structure after it has been realized. In that sense, it resembles a dress that should fit a certain body. As a dress it should be mounted and dismounted easily to host other similar elements. To close the similarity, as a dress it could be changed often, standing the criticality associated to its interaction with the external environment and the large strain it undergoes. It is clear that if that is the current configuration, a reduction of costs, time of maintenance (also meaning cost and aircraft usability), and even weight shall be targeted in novel configurations. Hybrid solutions considering metals and elastomers are envisaged to be exploited for more robust, cheap and light arrangements.

\subsection{Operations}

ALM techniques may play an important role also from the point of view of maintenance and repair procedures. In fact, intervention and substitutions could be performed on-demand and on-site, significantly reducing the stock size.

Augmented Reality, AR, could represent a valid answer to issues related to complex, unconventional systems, characterized by a high level of integration, [43]-[44]. Such tools could be driven by criteria suited for the specific case, elaborate alternative strategies and predict the achievable results and also the risks related. This approach, if supported by wide databases handled, for instance, by trained artificial neural networks, ANN, or any other kind of Artificial Intelligence; AI, could reduce operational times, dramatically, allowing a selection of the most appropriate process without a direct implementation, [45].

To enhance maintenance and repair processes, the use of health monitoring techniques combining structural and system features could be a winning solution. However, these systems, widely implemented in literature and in commercial applications, need some more evolutions for being implemented at a large extent on aircraft. In the case of adaptive structural systems, the presence of large sensor networks could be exploited also for monitoring the behavior of the different components, including structure, skins and actuation architectures. Indeed, a fascinating solution could regard the monitoring of the sensor networks themselves by cross-observations, solving one of the problems correlated to largely distributed monitoring systems. Additional interface with external systems could easily support and integrate the abovementioned AR tools, [46].

Other developments that could support maintenance are represented by self-repair and damage prevention techniques. Self-repair capability may be implemented through the use of the so-called self-healing materials, [47]-[48], able to recover some operational flaws to a certain extent. Highly integrated systems, even local, addressed to early detection of stress peaks may have a significant impact on maintenance, practically postponing any intervention.

Mainly, structure and actuation systems follow the usual repair paths, while something can be gained for sensors and skins. Non-reparable items suggest that they should be simply removed and substituted once failed. This can be done only if interfaces are designed and implemented properly, with a sort of plug-and-play philosophy since sensored components shall maintain the capability of being fed and transmit information. As already mentioned, wireless systems could be the final development stage of the ongoing researches.

Safety issues are perhaps the most critical. The tremendous increase of components and parts can shift the cumulative safety level downwards. This fact, associated to a predicted increase of the air traffic in the next future (after the COVID emergency is over), could lead to unacceptable values. It is a matter of fact that the onboard systems specifically devoted to move the aircraft wing should increase of a magnitude at least. Predictions move the expansion of air transportation by a similar factor in one-generation 
period. In order to leave the number of incidents unchanged, that means to increase the safety levels of the adopted components of an equal measure. In turn, and finally, this would mean to shift the reliability factor of the single component (probability of severe fault) from 1e-9 / 1e-10 to 1e-11 / 1e12, probably impossible to reach within the current technology scenario development. Redundancy is a trivial way to solve that issue, however associated to a tremendous impact in terms of costs, weight, volume, and architecture complexity. Another possibility is to relegate structural adaptations to non-primary flight elements, however reducing a lot the impact of such a technology.

A statement apart should be devoted to the use of non-conventional elements. While smart actuators can be a choice, to be discussed and approved time by time, morphing skin implementation is a necessity. In such cases, safety aspects shall be dealt with very carefully. On one side, the material may not be known very well, giving rise in turn to excessive reliability factors that shall necessarily consider the lack of info. On the other side, their installation shall always be associated to non-critical parts or, equivalently, to configuration whose disruption shall not bring to catastrophic events. In any case, reduction of interfaces may play a fundamental role in preserving the established safety levels without excessive penalty on the architecture of the reference system.

Table 5. Summary of Morphing System technology perspectives.

\begin{tabular}{|c|c|c|c|}
\hline Segment & Weakness & Mitigation approaches & Perspective \\
\hline Technology & $\begin{array}{l}\text { Number of parts } \\
\text { Number of interfaces } \\
\text { Number of joints } \\
\text { Cabling } \\
\text { Commercial availabil- } \\
\text { ity } \\
\text { Systems reliability }\end{array}$ & $\begin{array}{l}\text { ALM implementation } \\
\text { Bonding } \\
\text { Wireless networks } \\
\text { Multiplexed sensors } \\
\text { Targeted technology de- } \\
\text { velopment }\end{array}$ & $\begin{array}{l}\text { Close } \\
\text { Close } \\
\text { Not so far } \\
\text { Close } \\
\text { Far away }\end{array}$ \\
\hline Design & $\begin{array}{l}\text { Configurations } \\
\text { Number of joints } \\
\text { Lack of representative } \\
\text { tools } \\
\text { Interaction phenomena }\end{array}$ & $\begin{array}{l}\text { Augmented numerical } \\
\text { tools } \\
\text { Application on existing } \\
\text { aircraft } \\
\text { Augmented modelling of } \\
\text { details }\end{array}$ & $\begin{array}{l}\text { Not so far } \\
\text { Current } \\
\text { Close- }\end{array}$ \\
\hline $\begin{array}{l}\text { Manufactur- } \\
\text { ing and } \\
\text { Assembly }\end{array}$ & $\begin{array}{l}\text { Number of parts } \\
\text { Size of parts } \\
\text { Number of interfaces } \\
\text { Processes inadequate } \\
\text { Labile sub-structures } \\
\text { Skins }\end{array}$ & $\begin{array}{l}\text { ALM implementation } \\
\text { Process re-styling } \\
\text { Design of specific jigs and } \\
\text { tools } \\
\text { Hybrid skin solutions }\end{array}$ & $\begin{array}{l}\text { Close } \\
\text { Not so far } \\
\text { Current } \\
\text { Not so far }\end{array}$ \\
\hline Operations & $\begin{array}{l}\text { Stock size } \\
\text { Repair difficulty } \\
\text { Increased inspection in- } \\
\text { tervals } \\
\text { Processes inadequate }\end{array}$ & $\begin{array}{l}\text { ALM implementation } \\
\text { HM implementation } \\
\text { AR implementation } \\
\text { Process re-styling }\end{array}$ & $\begin{array}{l}\text { Close } \\
\text { Close } \\
\text { Current } \\
\text { Not so far }\end{array}$ \\
\hline Safety & $\begin{array}{l}\text { Increased number of } \\
\text { parts } \\
\text { Increased number of } \\
\text { subsystems } \\
\text { Unconventional materi- } \\
\text { als }\end{array}$ & $\begin{array}{l}\text { Lack of suited processes } \\
\text { Reliability factors approxi- } \\
\text { mation } \\
\text { Increased interfaces }\end{array}$ & $\begin{array}{l}\text { Complexity of analysis } \\
\text { Additional conserva- } \\
\text { tivisms } \\
\text { Process restyling }\end{array}$ \\
\hline
\end{tabular}

\section{Conclusions}


In spite of some negativity that could have been arisen from the analysis of the different components, a detailed survey of the posed problems and solutions shows that the perspectives are not far at all. In some cases, technology does already exist, while in other has already been studied for a long time. In other cases, studies are already present in literature, even though still at the first stage. Finally, even if not so diffused, some needs have already been implemented: for instance, manufacture and assembly of morphing structures has already occurred, even if to a minimal extent, for the tested prototypes... not that much at the date!

In some sense, the aim of achieving the realization of adaptive operative aircraft may work as a pusher for attaining results otherwise expected in a longer period. The morphing idea can leverage technology, in a word. Conversely, morphing needs could also arise aspects otherwise neglected that could instead have a definitive role in the correct assessment of a specific technology. If integrated vehicle health monitoring is considered, for instance, the availability of structural monitoring, shape control, and kinematic observation systems may lead to an extreme intelligence of the structural system as a whole, allowing for outstanding data extraction, and prediction.

There is also technology concurrence that could in turn foster adaptive structured development. Despite its ambition of reducing emissions, the full electric aircraft approach must face some important side effects. Among the others: energy storage of the batteries, [49], their intrinsic weight hardly compatible with lightweight requirements, [50]; safety and certification, including power system failure, battery thermal runaway and energy uncertainty, [51]. Morphing technology could contribute by enhancing the performance of the aircraft, for instance, by increasing its operational range, strongly penalized by the limited performance of the batteries. The joined adoption of a morphing approach with laminar wing technology could lead to a net efficiency increase of about $20 \%$, [52].

Morphing implies a drastic reinterpretation of conventional design. In general, DOF continuous distribution leads both to delocalization of its primary functions and to redundancy of them, with benefits in terms of aerodynamic efficiency, load distribution, and maneuverability [53]. The smoother shape of the deflected parts makes them more effective, with obvious benefits in terms of actuation power consumption [54]. Moreover, the high level of integration of subsystems favors clean architectures with a further improvement of performance. Finally, the just mentioned design reinterpretation foresees an optimization of the wing structure, with a net saving of weight with respect to conventional architectures, split into fixed and movable parts.

Moving to military, the so-called stealth combat aircraft may benefit of morphing technology, [55]. The smoothness of the surfaces, the absence of geometric discontinuities and asperities, jointly to materials of new generation with a modest reflection profile in the electromagnetic spectrum, help low observability. This justifies the large amount of theoretical and experimental investigations in this sense. An optimization process has been reported, [56], supporting the design of morphing and stealthy aerodynamic structures. Similar studies have been carried out for UAV, [57]. Impact of morphing on stealth properties has been also addressed from an industrial point of view, [58]. Examples of UCAV implementing morphing technology to support and enhance stealth features are diffused as for instance: CASC CH-7 UCAV and GJ-11 military drones, China, [59]; B-2 combat and monitoring drone, USA, [60].

Author Contributions: Conceptualization, SA, AC, ID, MG, and RP; methodology, SA, AC; formal analysis, MG; investigation, $\mathrm{AC}$; resources, $\mathrm{SA}$; data curation, $\mathrm{RP}$; writing - original draft preparation, SA, AC; writing - review and editing, ID, RP, and MG; visualization, SA; supervision, AC. All authors have read and agreed to the published version of the manuscript.

Funding: This research received no external funding.

Data Availability Statement: No new data were created or analyzed in this study. Data sharing is not applicable to this article. 
Conflicts of Interest: The authors declare no conflict of interest.

Ethics Statement: The study did not involve human or animals.

\section{References}

1. Flanagan, J.S.; Strutzenberg, R.C.; Myers, R.B.; Rodrian, J.E. Development and flight testing of a morphing aircraft, the NextGen MFX-1. In Proceedings of the 48th AIAA/ASME/ASCE/AHS/ASC Structures, Structural Dynamics, and Materials Conference, Honolulu, HI, USA, April 23-26, 2007.

2. Aerospace, Spanwise Adaptive Wing (LEW-TOPS-124), Shape memory alloy actuators reconfigure aircraft wings in flight. Available on line: https://technology.nasa.gov/patent/LEW-TOPS-124 (accessed on Novermber 13, 2021).

3. Jenett, B.E.; Calisch, S.; Cellucci, D.W.; et al. Digital Morphing Wing: Active Wing Shaping Concept Using Composite Lattice-Based Cellular Structures. Soft Robot. 2017, 4(1), 33-48.

4. Cramer, N.B.; Cellucci, D.W.; Formoso, O.B.; et al. Elastic shape morphing of ultralight structures by programmable assembly. Smart Mater. Struct. 2019, 28, 14 .

5. Cramer, N.B.; Tebyani, M.; Stone, K.; et al. Design and testing of fervor: flexible and reconfigurable voxel-based robot. In Proceedings of the IEEE/RSJ International Conference on Intelligent Robots and Systems (IROS), Vancouver, BC, Canada, September 24-28, 2017.

6. Holle, A.A. Plane and the like for aeroplanes. United States Patent N.1225711. Priority Date, December 22, 1916; Publication Date, May 8, 1917.

7. $\quad$ Parker, H.F. 1920. The Parker variable camber wing. NACA Technical Report 77.

8. Hardy, R. AFTI/F-111 mission adaptive wing technology demonstration program. In Proceedings of the 1983 AIAA Aircraft Prototype and Technology Demonstrator Symposium, Air Force Museum, Dayton, OH, USA, March 23-24, 1983.

9. Bonnema, K.L. 1988. AFTI/F-111 mission adaptive wing briefing to industry. Air Force Wright Aeronautical Laboratories, Air Force Systems Command, Wright-Patterson Air Force Base, AFWAL Technical Report TR-88-3082. ADA202467.

10. Hilbig, R.; Koerner, H. Intelligente Tragfluegel - Aerodynamische Entwicklungsrichtungen fuer Verkehrsflugzeuge. In Proceedings of Deutsche Gesellschaft fuer Luft-und Raumfahrt (DGLR) Annual Convention, Hamburg, Germany, October 13, 1984 [German].

11. Woelcken, P.C.; Papadopoulos, M. (Eds.). Smart Intelligent Aircraft Structures (SARISTU)-Proceedings of the Final Project Conference, $1^{\text {st }}$ ed.; Springer International Publishing, Cham, Switzerland, 2016; pp. 1039.

12. NASA Tests Revolutionary Shape Changing Aircraft Flap for the First Time, Release 14-308, Nov 7, 2014. Available online: https://www.nasa.gov/press/2014/november/nasa-tests-revolutionary-shape-changing-aircraft-flap-for-the-first-time (accessed on Novermber 15, 2021).

13. Nguyen, N.T.; Ting, E.; Lebofsky S. Aeroelastic analysis of wind tunnel test data of a flexible wing with a variable camber continuous trailing edge flap (VCCTEF). In Proceedings of the $56^{\text {th }}$ AIAA/ASCE/AHS/ASC Structures, Structural Dynamics, and Materials Conference, Kissimmee, FL, USA, January 5-9, 2015.

14. Noviello, M.C.; Dimino, I.; Concilio, A.; Amoroso, F.; Pecora, R. Aeroelastic Assessments and Functional Hazard Analysis of a Regional Aircraft Equipped with Morphing Winglets. Aerospace 2019, 6(10), 19.

15. Sponsler, G.C.; Dare, E.; Gignoux, N..; Rubin, N.N. 1973. The F-4 and the F-14. Columbia Research Corporation, Naval Analysis Programs - Office of Naval Research Grant N00014-72-C-0339. AD0910249.

16. Goff, W.E. Droop nose. Flight Int. 1971, 100, 257-8.

17. Kudva, J. N.; Martin, C.A.; Scherer, L.B.; et al. Overview of the DARPA/AFRL/NASA smart wing program. In Proceedings of the SPIE's $6^{\text {th }}$ Symposium on Smart Structures and Materials, Industrial and Commercial Applications of Smart Structures Technologies, Newport Beach, CA, USA. March 1-5, 1999.

18. Allison, S.G.; Fox, R.L.; Froggatt, M.E.; Childers, B.A. THUNDER piezoelectric actuators as a method of stretch-tuning an optical fiber grating. In Proceedings of the SPIE $7^{\text {th }}$ Annual International Symposium on Smart Structures and Materials, Industrial and Commercial Applications of Smart Structures Technologies, Newport Beach, CA, USA. March 6-9, 2000.

19. Mehrpouya, M.; Gisario, A.; Broggiato, G.B.; et al. Effect of welding parameters on functionality of dissimilar laser-welded NiTi superelastic (SE) to shape memory effect (SME) wires. Int J Adv Manuf Technol. 2019, 103, 1593-1601.

20. Drossel, W.G.; Junker, T.; Bucht, A.; et al. Evaluation of Shape Memory Alloy Bulk Actuators for Wear Compensation in Ball Screw Drives. IFAC-PapersOnLine, 2016, 49(21), 88-94.

21. Aroganam, G.; Manivannan, N.; Harrison, D. Review on Wearable Technology Sensors Used in Consumer Sport Applications. Sensors (Basel), 2019, 19(9), 1983.

22. Baitab, D.; Majid, D.L.A.H.A.; Abdullah, E.; Hamid, M. A review of techniques for embedding shape memory alloy (SMA) wires in smart woven composites. International Journal of Engineering and Technology (UAE), 2018, 7, 129-136.

23. Materials today, Efficient and unique - DuraAct power piezo composite patch transducer with multilayer ceramics uses d33 effect. Available online: https://www.materialstoday.com/electronic-properties/products/duraact-power-piezo-composite-patch-transducer (accessed on December 3, 2021).

24. IATA, Airline Maintenance Cost Executive Commentary FY2019 Data. Available online: https://www.iata.org/contentassets/bf8ca67c8bcd4358b3d004b0d6d0916f/fy2019-mctg-report public.pdf (accessed on December 3, 2021).

25. Zheng, M.; Vu, K.K.; Liew, J.Y.R. Aircraft morphing wing concepts with radical geometry change. The IES Journal Part A: Civil E Structural Engineering, 2012, 3(3), 188-195. 
26. Ciminello, M.; Ameduri, S.; Romano, F.; Concilio, A. Impact area and debonding line detection assessment by cross-correlation analysis and distributed sensing. Optical Fiber Technology, 2020, 58, 102245.

27. Ameduri, S.; Ciminello, M. Surface Bonding Graphene-Based Elastomeric Sensor: Preliminary Characterization of Adhesion Strength. In Proceedings of the ASME 2019 Conference on Smart Materials, Adaptive Structures and Intelligent Systems, Louisville, Kentucky, USA. September 9-11, 2019.

28. Pellone, L.; Ameduri, S.; Favaloro, N.; Concilio, A. SMA-Based System for Environmental Sensors Released from an Unmanned Aerial Vehicle. Aerospace, 2017, 4(1), 22.

29. Ameduri, S.; Concilio, A.; Favaloro, N.; Pellone, L. A Shape Memory Alloy Application for Compact Unmanned Aerial Vehicles. Aerospace, 2016, 3(2), 18.

30. Xu, L.; Solomou, A.; Lagoudas, D. A Three-Dimensional Constitutive Modeling for Shape Memory Alloys Considering Two-Way Shape Memory Effect and Transformation-Induced Plasticity. In Proceedings of the AIAA Scitech 2019 Forum, San Diego, California, USA. January 7-11, 2019.

31. Phys.org, NASA tests new alloy to fold wings in flight. Available online: https://phys.org/news/2018-01-nasa-alloy-wingsflight.html, (accessed on December 3, 2021).

32. Bashir, M.; Rajendran, P. Recent Trends in Piezoelectric Smart Materials and Its Actuators for Morphing Aircraft Development. IREME, 2019, 13(2).

33. Shivashankar, P.; Gopalakrishnan S. Review on the use of piezoelectric materials for active vibration, noise, and flow control. Smart Mater. Struct., 2020, 29, 053001.

34. Jani, J.M.; Leary, M.; Subic, A.; Gibson, M.A. A review of shape memory alloy research, applications and opportunities. Mater. Des., 2014, 56, 1078-1113.

35. Wang, Z.P.; Poh, L.H.; Zhu, Y.; et al. Systematic design of tetra-petals auxetic structures with stiffness constraint. Mater. Des., 2019, 170, 107669.

36. Chillara, V.S.C.; Dapino, M.J. Review of Morphing Laminated Composites. Appl Mech Rev, 2020, 72(1), 010801.

37. Nicassio, F.; Scarselli, G.; Pinto, F.; et al. Low energy actuation technique of bistable composites for aircraft morphing. Aerosp Sci Technol, 2018, 75, 35-46.

38. Ameduri, S.; Concilio, A. Morphing wings review: aims, challenges, and current open issues of a technology. Proc Inst Mech Eng C J Mech Eng Sci, 2020, First Published August 2.

39. Ajaj, R.M.; Beaverstock, C.S.; Friswell, M.I. Morphing aircraft: The need for a new design philosophy. Aerosp Sci Technol, 2016, 49, 154-166.

40. Prescouter, The Top 6 Technologies for Improving Aircraft Fuel Efficiency. Available on line: https://www.prescouter.com/2018/01/technologies-improving-aircraft-fuel-efficiency, (accessed on December 3, 2021).

41. Piedade, A.P. 4D Printing: The Shape-Morphing in Additive Manufacturing. J. Funct. Biomater, 2019, $10(1), 9$.

42. Goh, G.D.; Agarwala, S.; Goh, G.L.; et al. Additive manufacturing in unmanned aerial vehicles (UAVs): Challenges and potential. Aerosp Sci Technol, 2017, 63, 140-151.

43. Intelligent Aerospace, New Jamco augmented reality technology creates efficient maintenance service. Available on line: https://www.intelligent-aerospace.com/commercial/article/14168824/augmented-reality-aircraft-maintenance (accessed on December 4, 2021).

44. De Crescenzio, F.; Fantini, M.; Persiani, F.; et al. Augmented Reality for Aircraft Maintenance Training and Operations. IEEE Comput Graph Appl, 2011, 31(1), 96-101.

45. Soumitra, P.; Kunal, K.; Devashish, J.; et al. Application of Artificial Neural Networks in Aircraft Maintenance, Repair and Overhaul Solutions. In Proceedings of the International Conference on Total Engineering, Analysis and Manufacturing Technologies, Bangalore, India. September 22-24, 2008.

46. Jeong, Y.; Son, S.; Jeong, E.; Lee, B. An Integrated Self-Diagnosis System for an Autonomous Vehicle Based on an IoT Gateway and Deep Learning. Appl. Sci., 2018, 8(7), 1164.

47. Das, R.; Melchior, C.; Karumbaiah, K.M. Self-healing composites for aerospace applications. In Advanced Composite Materials for Aerospace Engineering Processing, Properties and Applications, 1'st ed.; Rana, S., Fangueiro, R., Eds.; Publisher: Woodhead Publishing, Duxford, UK, 2016; Chapter 11, 333-364.

48. Nnamchi, P.S.; Obayi, C.S. Self-Healing in Titanium Alloys: A Materials Science Perspective. In Advanced Functional Materials, $1^{\text {st }}$ ed.; Tasaltin, N., Nnamchi, P.S., Saud, S., Eds.; Publisher: In-Tech Open, London, UK, 2020; Chapter 9.

49. The conversation, Electric planes are here - but they won't solve flying's $\mathrm{CO}_{2}$ problem. Available on line: $\underline{\mathrm{https}} / / / \mathrm{thecon-}$ versation.com/electric-planes-are-here-but-they-wont-solve-flyings-co-problem-125900 (accessed on December 4, 2021).

50. Smithsonian Magazine, Why Aren't There Electric Airplanes Yet? It Comes Down to Batteries. Available on line: https://www.smithsonianmag.com/innovation/why-arent-there-electric-airplanes-yet-it-comes-down-batteries$\underline{180970909 /(a c c e s s e d ~ o n ~ D e c e m b e r ~ 4, ~ 2021) . ~}$

51. Courtin, C.; Hansman, R.J. 2018. Safety considerations in emerging electric aircraft architectures, Report No. ICAT-2018-07.

52. Aerospace Testing International, Airbus tests laminar flow wing. Available on line: https://www.aerospacetestinginternational.com/videos/airbus-tests-laminar-flow-wing.html (accessed on December 4, 2021).

53. Ajaj, R.M.; Beaverstock, C.S.; Friswell, M.I. Morphing aircraft: The need for a new design philosophy. Aerosp Sci Technol, 2016, 49, 154-166. 
54. Dimino, I.; Amendola, G.; Di Giampaolo, B.; et al. Preliminary design of an actuation system for a morphing winglet. In Proceedings of the 8th International Conference on Mechanical and Aerospace Engineering (ICMAE), Prague, Czechia, July 22-25, 2017.

55. The Warzone, The Future Of Stealth Is "Morphing Wing" Technology, But Will The B-21 Feature It? Available on line: https://www.thedrive.com/the-war-zone/15413/the-future-of-stealth-is-in-morphing-wing-technology-will-the-b-21-feature-it (accessed on December 4, 2021).

56. Li, M.; Bai, J.; Li, L.; et al. A gradient-based aero-stealth optimization design method for flying wing aircraft. Aerosp Sci Technol, 2019, 92, 156-169.

57. Hassanalian, M.; Quintana, A.; Abdelkefi, A. Morphing and growing micro unmanned air vehicle: Sizing process and stability. Aerosp Sci Technol, 2018, 78, 130-146.

58. Apuleo, G. Aircraft Morphing-An Industry Vision, In Morphing Wing Technologies Large Commercial Aircraft and Helicopters Scenario, $1^{\text {st }}$ ed.; Concilio, A., Dimino, I., Lecce, L., Pecora, R., Eds.; Publisher: Butterworth-Heinemann, Woodhead Publishing, Oxford, UK, 2017; Chapter 2, 85-101.

59. The Warzone, China Showcases Stealthier Sharp Sword Unmanned Combat Air Vehicle Configuration. Available on line: https://www.thedrive.com/the-war-zone/30111/china-showcases-stealthier-sharp-sword-unmanned-combat-air-vehicleconfiguration (accessed on December 4, 2021).

60. Aerospace in Canada, NASA and MIT's “Morphing Wing" Concept. Available on line: https://aerospaceincanada.com/index.php/2019/04/26/nasa-and-mits-morphing-wing-concept (accessed on December 4, 2021). 